\title{
A Determination of the Relationship between Emotional Intelligence and Critical Thinking among Human Resources Practitioners on the Copperbelt Province, Zambia
}

\author{
Adamson Mukhalipi ${ }^{*}$, Agabu Shane ${ }^{2}$ \\ ${ }^{1}$ Zambia Institute of Human Resource Management, Kitwe Branch, Zambia \\ ${ }^{2}$ School of Mines and Mineral Sciences, The Copperbelt University, Kitwe, Zambia \\ Email: ^adamsonmukhalipi@ymail.com
}

How to cite this paper: Mukhalipi, A. and Shane, A. (2019) A Determination of the Relationship between Emotional Intelligence and Critical Thinking among Human Resources Practitioners on the Copperbelt Province, Zambia. Open Access Library Journal, 6: e5850.

https://doi.org/10.4236/oalib.1105850

Received: October 12, 2019

Accepted: October 26, 2019

Published: October 29, 2019

Copyright $\odot 2019$ by author(s) and Open Access Library Inc.

This work is licensed under the Creative Commons Attribution International License (CC BY 4.0).

http://creativecommons.org/licenses/by/4.0/

\begin{abstract}
The purpose of this paper was to determine the relationship between emotional intelligence and critical thinking among Human Resource Practitioners. To do so, 63 were randomly selected from $75 \mathrm{HR}$ practitioners by the Sample Size based on Desired Accuracy adopted from (Gill et al., 2010) and answered to the survey questionnaires derived from Emotional Intelligence based the Emotional Competency Profiler (ECP) and Critical thinking skills based on the California Critical Thinking Skills Test (CCTST). SPSS Version 20 analyzed the data by using descriptive statistics T-test and F-tests level of significance was determined at 0.05 . A correlational analysis was conducted to examine the relationship between Emotional Intelligence and Critical Thinking. The analysis was significant, $\mathrm{r}(19)=0.725, \mathrm{p}<0.001$. Emotional intelligence and critical thinking among Human Resource Practitioners do come with a significant relationship. However, the weakness of this study is attributed to the small sample size and hence a formal study be conducted targeting a big sample size in the near future to ascertain if there is a significant relationship between the two variables. It is recommended that Emotional Intelligence and Critical thinking skills be included in Diploma in $\mathrm{Hu}-$ man Resource Management and also in Bachelor of Arts in Human Resources Management respectively to enhance these skills in students to enable them solve complex Human Relationship problems at the workplaces.
\end{abstract}

\section{Subject Areas}

Business Research Methods 


\section{Keywords}

Critical Thinking, Emotional Intelligence, Human Resource Practitioners

\section{Introduction}

As early as 1980s the concept of human resource management gained ground at the expense of personal management and that during the middle part of the century, emphasis shifted to the employee's productivity [1]. In recent decades, Human Resource Management (HRM) has focused on increased concern on quality of working life, total quality management and workers organizations and project management aspects [1]. Maxiwell (2006), observed that the success, fulfillment and happiness of individual employees was depended upon one's ability to relate effectively with others [2]. Gitlow, et al. (2009) noted that all these processes were about relations between people and processes which have existed in all the facets of organizations, and that it was therefore crucial to understand them [3].

Therefore, with businesses crossing boundaries, managing people could not be restricted to the ways of the parent country. Usunier and Lee (2005) observed that while globalization was a key issue for international strategies, it was difficult to examine it because demand that existed in the actual market could not fully be separated from supply. It was in this vein that HRM today needed to focus on horizontal authority and reduce hierarchy [4]. As managers were given the responsibility of managing people, the HRPs were expected to support and facilitate line managers in this task and not to control. Therefore, human resource planning should be seen as a pro-action and not forced with corporate level planning [1]. Human resource issues were expected to be treated strategically in an integrated manner since employees were viewed as subjects with the potential for growth and development [1]. Well (2003), defined Strategy as the means for achieving a long-range strategic goal; explaining how the goal would be attained [4] D'Souza (2003) observed that leadership concerned itself with achieving results through accomplishing the common task, remaining a cohesive social unity to attain the set objectives and addressing individual needs of the group [5].

The purpose of human resource management was to identify individual employee potential and develop it in line with the adaptive needs of an organization [1]. To the contrary, [6], observed that from 2019 and onwards, Human Resource (HR) software would be moving beyond its base functionality of benefits management, recruitment, time and attendance, professional development and other standard features. Though these features would still be integral to the technology, more advanced tools would emerge. Automation has an overaching theme for HR innovation, with many functions becoming completely digitized, eliminating the need for human involvement. Benefit associated with HR inno- 
vations such as artificial intelligence/machine learning, robotics and autonomous agents, virtual and augmented reality, performance management and real time feedback and monitoring, biometric time tracking and security, wearable tech and middleware would be useful in providing timely services [6].

As could be seen from different features described above, HRM could be viewed as a strenuous job, which would take place in a stressful work environment [6]. Such environment requires Human Resources Practitioners (HRPs) to think critically and be able to manage their emotions and those of their workmates and customers in order to provide quality and timely service delivery [6].

Therefore, critical thinking and emotional intelligence would be vital ingredients that would influence the HRPs' decision making, use of facts or evidence and other information to practice their profession, negotiate with the contractors, unions, communicate with employees, and provide responsive and timely quality of services to their clients. Human Resources Practitioners (HRPs) should possess the skills of critical thinking and emotional intelligence in order to execute their duties diligently, make prudent decision and provide timely and responsive service delivery to the customers. For HRPs to be the best people centered persons, they must possess both critical thinking and emotional intelligence skills. Elder, L., (1997) in [7] stated that critical thinking provides a vital link between intelligence and the emotions and seeks to determine the quality emotional intelligence [8]. It was emphasized that emotions and thoughts should not be considered as different concepts, as they were indispensable to each other, and because emotions formed the basis of thoughts [9]. An individual within advanced critical thinking abilities was also likely to have high emotional intelligence [10].

However, despite the numerous research studies conducted on the subject matter of critical thinking and emotional intelligence among various professional, there was no research conducted to assess the relationship critical thinking and emotional intelligence in HR Practitioners.

\section{Emotional Intelligence}

Leasa (2018), defined Emotional Intelligence as a person's ability to motivate oneself, ready to remain in difficult circumstances, able to manage the condition of the heart and control so as not to think about something excessively, to show empathy, and have hope [9] [10]. Emotional intelligence was a useful skill in awakening a person to recognize emotional responses and to use them wisely at the right time and condition.

However, (Larson, 2012) notes that the advent of communication tools such as smartphones, tablets and instant messaging have made the quality of communication in the workplaces difficult [11]. Goleman, (1995) notes that the pace of increased change obtaining at workplaces was making greater demands on the employee's emotional, cognitive and physical resources and were making these sets of abilities increasingly important [9]. Goleman, D., also argues that since 
majority of concerns in organizations involve people performing different roles, emotional intelligence must become a determining factor for effective people management and suggests that emotional competencies need to be identified and measured in order to predict performance resulting in its effectiveness and enhance human capital [9].

Larson (2012), outlines the dimensions measured in an emotional intelligence assessment as follows: Self-Awareness, Self-Regulation, Motivation, Empathy and Social Skills-all of which were important for improving communication. In the case of our EQ assessment, well-developed Social Skills refer to a proficiency in managing relationships and building networks [11].

\section{Critical Thinking}

Rubenfield and Schefer (1999), considers critical thinking as the key element in professional and responsible practice [12]. Moore and Parker (2009), define critical thinking as the careful application of reason in the determination of whether a claim was true or false [13]. Therefore, critical thinking was the intellectually disciplined process of actively and skillfully conceptualizing, applying, analyzing, synthesizing, and/or evaluating information gathered from, or generated by, observation, experience, reflection, reasoning, or communication, as a guide to belief and action. In its exemplary form, this was based on universal intellectual values that transcend subject matter divisions: Claim, accuracy, precision, consistency, relevance, sound evidence, good reasons, depth, breadth, and fairness. Similarly, critical thinking is also defined as a process involving mental operations such as induction, deduction, classification, and reasoning [10].

Therefore, critical thinking is characterized by students' ability to define patterns, make connections, and solve new problems. A person who thinks critically has certain characteristics such as always showing evidence through observation or judgment based on criteria with appropriate methods, techniques, and decision making in solving a particular problem. Critical thinking implies deeper thought processes, able to explore information, and to act wisely in considering something before making the best rational decision [10].

Leasa, (2018), posits that HRPs need to possess critical thinking skills in order to implement evidence based practices, timely and effectively respond to their customers based on facts or evidence and provide their customers with undivided attention [10]. Further, the HRPs should possess critical thinking and emotional intelligence skills to identify their customer's needs, to make prudent decisions, to evaluate complex information about different claims, complaints presented, statements, evidence or facts submitted to their offices for their attention [12].

It has been observed that thinking skill was an important life skill in learning in the $21^{\text {st }}$ century as they were considered important in determining a person's cognitive development. Someone who has critical thinking skills always strived to develop his curiosity, he was motivated to solve problems, and think optimis- 
tically about everything before making the best decisions [14]. According to Anderson (2015) the importance of critical skills in the HRPs were as follows [15]:

1) Adding value with the metrics we collect.

2) Aids in the selection of talent.

3) Key concepts of learning versus training.

4) HRPs are connectors of disciplines.

5) Making good decisions is good business.

\section{Emotional Intelligence and Critical Thinking}

Emotional intelligence was functioned optimally to improve intellectual intelligence. Emotional intelligence in the development of individuals was closely related to cognitive processes, as it could be observed at the age before preschool. It allowed more social relationships that impact on the development of emotional intelligence [9]. There was no intellectual intelligence without the empowerment of thinking; therefore, the thinking skill was an area of intellectual intelligence that needs to be considered, because it had a relationship with emotional intelligence. Thus, emotional intelligence could be a predictor of critical thinking skills.

\section{Methodology}

This study took a descriptive research design. The sample size consisted of HR Practitioners on the Copperbelt Province. After compiling a list of all HR Practitioner on the Copperbelt, for determining the size of sample, we have used the Gill et al, (2010), Sample Size Based on Desired Accuracy Table 1 below. Out of the population size of 75 , at $5 \%$ margin of error, $63 \mathrm{HR}$ practitioners were selected to participate in responding to the questionnaires on Emotional Intelligence and Critical Thinking, only 19 questionnaires were collected [16].

\section{Data Collection Tools}

\subsection{Emotional Intelligence Questionnaire}

As regards to measurements, [17] measured, emotional intelligence based the Emotional Competency Profiler (ECP). The ECP used a six-point scale to measure levels of current emotional intelligence competence. The higher the score is on the current behavior scale, the higher the level of emotional intelligence

Table 1. Sample size based on desired accuracy.

\begin{tabular}{ccccccc}
\hline & \multicolumn{6}{c}{ Variance of the population $\mathrm{P}=50 \%$} \\
\cline { 2 - 7 } & Confidence level & \multicolumn{7}{c}{$95 \%$} & Margin of Error & Confidence level & 99\% Margin of Error \\
\hline Population Size & 5 & 3 & 1 & 5 & 3 & 1 \\
\hline 50 & 44 & 48 & 50 & 46 & 49 & 50 \\
75 & 63 & 70 & 74 & 67 & 72 & 75 \\
\hline
\end{tabular}

Source: [16]. 
demonstrated by the individual Human Resource Officer. This study therefore measure emotional intelligence based on a 4-point Likert scale ranging from 1Strongly Disagree to 4-Strongly Agree.

\subsection{Critical Thinking Questionnaire}

Critical thinking skills were measured in five subgroups by California Critical Thinking Skills Test (CCTST). It was based on the 75 items that measure critical thinking. It was anchored on a 4 point scale ranging from 1 -Strongly Disagree to 4-Strongly Agree [18].

\subsection{Reliability Test}

To test the reliability of the research instrument, Cronbach's coefficient alpha was used through SPSS to examine the internal consistency of items of the scale.

Table 2 shows that e that Cronbach's alpha is 0.968 , which indicates a high level of internal consistency for the scale with this specific sample.

\section{Results}

Results (Table 3) showed that shows that the mean score of critical thinking is 3.0456 with standard deviation of $\mathrm{SD}=0.62490$ and the mean score of emotional intelligence is $\mathrm{M}=3.9590$ with standard deviation of $\mathrm{SD}=0.38726$.

Table 4 shows that there is no significant difference between emotional intelligence and critical thinking with different years of work experience $(\mathrm{P}>0.05)$.

Table 5 shows that there is no significant difference between emotional intelligence and different levels of Education qualifications $(P>0.05)$. In contrary, significant difference was obtained between critical thinking with different levels of Education qualifications $(\mathrm{P}<0.05)$.

Table 6 shows that there is no significant difference between emotional intelligence and critical thinking with different ages of birth $(\mathrm{P}>0.05)$.

A correlational analysis was conducted to examine the relationship between Emotional Intelligence and Critical Thinking. The analysis was significant, $r(19)$ $=0.725, p<0.001$. Participants with higher emotional intelligence scores reported positive critical thinking (Table 7).

Table 2. Reliability statistics.

\begin{tabular}{ccc}
\hline Cronbach's Alpha & Cronbach's Alpha Based on Standardized Items & N of Items \\
\hline 0.968 & 0.976 & 134
\end{tabular}

Table 3. Descriptive indicators of research variables

\begin{tabular}{cccccc}
\hline & $\mathrm{N}$ & Minimum & Maximum & Mean & Std. Deviation \\
\hline Emotional Intelligence & 19 & 2.76 & 4.41 & 3.9590 & 0.38726 \\
Critical Thinking & 19 & 1.85 & 4.52 & 3.0456 & 0.62490 \\
\hline
\end{tabular}


Table 4. Descriptive statistics, analysis of variance of emotional intelligence and critical thinking by years of work experience.

\begin{tabular}{|c|c|c|c|c|c|c|c|}
\hline Variables & Years of Work Experience & Number & Mean & Standard Deviation & $\mathrm{df}$ & F-Test Value & Significance Level \\
\hline \multirow{4}{*}{ Emotional Intelligence } & Below 10 years & 11 & 3.9476 & 0.15282 & & \multirow{4}{*}{0.098} & \multirow{4}{*}{0.960} \\
\hline & $11-20$ years & 4 & 3.9788 & 0.07237 & 3 & & \\
\hline & $21-30$ years & 3 & 4.0339 & 0.05085 & 15 & & \\
\hline & Above 31 years & 1 & 3.7797 & 0. & & & \\
\hline \multirow{4}{*}{ Critical Thinking } & Below 10 years & 11 & 2.9806 & 0.19715 & & \multirow{4}{*}{0.273} & \multirow{4}{*}{0.844} \\
\hline & $11-20$ years & 4 & 3.3067 & 0.43625 & 3 & & \\
\hline & $21-30$ years & 3 & 2.9244 & 0.13252 & 15 & & \\
\hline & Above 31 years & 1 & 3.0800 & & & & \\
\hline
\end{tabular}

Table 5. Descriptive statistics and analysis of variance of emotional intelligence and critical thinking with different levels of education qualifications.

\begin{tabular}{|c|c|c|c|c|c|c|c|}
\hline Variables & Educational Level & Number & Mean & Standard Deviation & $\mathrm{df}$ & F-Test Value & Significance Level \\
\hline \multirow{4}{*}{ Emotional Intelligence } & Diploma & 3 & 3.6384 & 0.77195 & & \multirow{4}{*}{2.358} & \multirow{4}{*}{0.113} \\
\hline & First Degree & 12 & 3.9195 & 0.24015 & 3 & & \\
\hline & Masters Degree & 3 & 4.3616 & 0.06417 & 15 & & \\
\hline & Diploma in HR & 1 & 4.1864 & & & & \\
\hline \multirow{4}{*}{ Critical Thinking } & Diploma & 3 & 2.6133 & 0.68599 & & \multirow{4}{*}{11.410} & \multirow{4}{*}{0.000} \\
\hline & First Degree & 12 & 2.8444 & 0.31219 & 3 & & \\
\hline & Masters Degree & 3 & 3.7911 & 0.25345 & 15 & & \\
\hline & Diploma in HR & 1 & 4.5200 & & & & \\
\hline
\end{tabular}

Table 6. Descriptive statistics and analysis of variance of emotional intelligence and critical thinking with different ages of birth.

\begin{tabular}{cccccccc}
\hline Variables & Years of Birth & Number & Mean & Standard Deviation & df & F-Test Value & Significance Level \\
\hline \multirow{2}{*}{ Emotional Intelligence } & $21-40$ years & 14 & 3.9492 & 0.44601 & 1 & 0.032 & 0.859 \\
& $41-60$ years & 5 & 3.9864 & 0.16450 & 17 & & 0.998 \\
Critical Thinking & $21-40$ years & 14 & 2.9600 & 0.59768 & 1 & 0.998 \\
& $41-60$ years & 5 & 3.2853 & 0.70626 & 17 & & \\
\hline
\end{tabular}

Table 7. Pearson correlation coefficient.

\begin{tabular}{cccc}
\hline & & Emotional Intelligence & Critical Thinking \\
\hline & Pearson Correlation & 1 & $0.725^{* *}$ \\
Emotional Intelligence & Sig. (2-tailed) & & 0.000 \\
& $\mathrm{~N}$ & 19 & 19 \\
& Pearson Correlation & $0.725^{* *}$ & 1 \\
Critical Thinking & Sig. (2-tailed) & 0.000 & 19 \\
& $\mathrm{~N}$ & 19 & \\
\hline
\end{tabular}

${ }^{* *}$ Correlation is significant at the 0.01 level (2-tailed). 


\section{Discussion}

The purpose of the study was to determine the relationship between emotional intelligence and critical thinking among Human Resource Practitioners.

When literature is reviewed, there are some results supporting that emotional intelligence is study revealed that there was correlation between emotional intelligence and critical thinking skills [11] [19] [20]. However, in the study of Kaya, Senyuva and Bodur (2018), revealed that there was no relationship between sub-dimensions of emotional intelligence respectively; awareness of emotions, empathy, social skills in the first academic year and critical thinking disposition and the end of academic year [7].

Emotional intelligence and critical thinking were viewed as pillars of success, especially when they were raised in the area of education. Since the body and mind were closely associated with each other, what man thought about, was under the influence of emotions and the surrounding. The more powerful the human was in understanding his thoughts, the more control he would have on them and the more changes he could make on them if necessary. In other words, the result of perceptive and rational thinking was success in different aspects of life. The manager who has higher ability of critical thinking with high emotional intelligence and creativity was certainly more successful than the other who lacked of these features in the life and work [7] [18].

\section{Conclusion}

In summary, this paper has sought to determine the relationship between emotional intelligence and critical thinking among Human Resource Practitioners. The result of this study can support future research on emotional intelligence and critical thinking among HR Practitioners. Although many empirical studies have been undertaken to assess the correlation between emotional intelligence and critical thinking among other professionals, there is still need for a detailed research to be conducted among HR practitioners since the sample size used in this study was very small and not representative.

\section{Conflicts of Interest}

The authors declare no conflicts of interest regarding the publication of this paper.

\section{References}

[1] Sanghi, S. (2014) Human Resource Management. Vikas Publishing House Pvt Ltd., Aminjikarai, Chennai, 10-11.

[2] Maxiwell, J. (2006) Be a People Person: Effective Leadership through Effective Relationship. Word Alive Publishers, Nairobi, 10-13.

[3] Gitlow, H.S., Oppenheim, A., Oppenheim, R. and Levine, D.M. (2005) Quality Management. 3rd Edition, Tata McGraw Hill Education Private Limited, New York, 3. 
[4] Wells, D.L. (2003) Strategic Management for Senior Leaders: A Handbook for Implementation. Department of the Navy Total Quality Leadership Office, 1-10.

[5] Usunier, J. and Lee, J.A. (2005) Marketing across Cultures. 4th Edition, Pearson Education Limited, London, 118-130.

[6] D’Souza, A. (2003) Leadership: Trilogy on Leadership and Effective Management. Paulines Publications, Nairobi, 1-60.

[7] https://selecthub.com/hris/future-of-hr-software-trends/09.08.19

[8] Kaya, H., Şenyuva, E. and Bodur, G. (2018) The Relationship between Critical Thinking and Emotional Intelligence in Nursing Students: A Longitudinal Study. Nurse Education Today, 68, 26-32. https://doi.org/10.1016/j.nedt.2018.05.024

[9] Elder, L. (1997) Critical Thinking: The Key to Emotional Intelligent. Journal of Developmental Education, 21, 40-42.

[10] Daniel, G. (1995) Emotional Intelligence. 6th Edition, Roshd Publications, Tehran.

[11] Dutoğlu, G. and Tuncel, M. (2008) The Relationship between Candidate Teachers' Critical Thinking Tendencies and Their Emotional Intelligence Levels. AbantIzzet Baysal Universitesi Egitim Fakultesi Dergisi, 8, 11-32.

[12] https://rojoconsultancy.com/emotional-intelligence-vital-tech-enabled-world

[13] Rubenfeld, M.G. and Scheffer, B.K. (1995). Critical Thinking in Nursing: An Interactive Approach. American Journal of Nursing, 96, 16M. https://doi.org/10.1097/00000446-199612000-00023

[14] Moore, B.N. and Parker, R. (2009) Critical Thinking. 9th Edition, California State University, McGraw-Hill Higher Education, New York, 1-17

[15] Anderson, C. (2015) Critical Thinking Skills for the HR Professional. HR Summit, 15 October 2015.

[16] Gill, J., Johnson, P. and Clark. M. (2010) Research Methods for Managers. SAGE Publications, Washington DC.

[17] Mukhalipi, A. (2009) Employee Performance and Leader's Emotional Intelligence: A Case of Kitwe DHMT. The Copperbelt University, Zambia, 1-97

[18] John, C. (2016) The Philosopher's Way Thinking Critically about Profound Ideas. 5th Edition, Pearson Education, New York, 402-408.

[19] Afshar, H.S. and Rahimi, M. (2014) The Relationship among Critical Thinking, Emotional Intelligence, and Speaking Abilities of Iranian EFL Learners. ProcediaSocial and Behavioral Sciences, 136, 75-79. https://doi.org/10.1016/j.sbspro.2014.05.291

[20] Saremi, H. and Sosan, B. (2015) The Relationship between Critical Thinking with Emotional Intelligence and Creativity among Elementary School Principals in Bojnord City, Iran. International Journal of Life Sciences, 9, 33-40. https://doi.org/10.3126/ijls.v9i6.12684 